OPEN ACCESS

Edited by:

Francisco Ruiz-Fons, Instituto de Investigación en Recursos Cinegéticos IREC (CSIC-UCLM-JCCM), Spain

Reviewed by: Fedor Korennoy,

Federal Center for Animal Health (FGBI ARRIAH), Russia Jorge Ramón López-Olvera, Universitat Autònoma de Barcelona, Spain

${ }^{*}$ Correspondence:

Marie-Frédérique Le Potier marie-frederique.lepotier@anses.fr

these authors have contributed equally to this work.

Specialty section: This article was submitted to Veterinary Epidemiology and Economics,

a section of the journal Frontiers in Veterinary Science

Received: 21 July 2017 Accepted: 03 January 2018 Published: 24 January 2018

Citation:

Charrier F, Rossi S, Jori F,

Maestrini O, Richomme $C$, Casabianca F, Ducrot C, Jouve J, Pavio N and Le Potier MF (2018) Aujeszky's Disease and Hepatitis E

Viruses Transmission between Domestic Pigs and Wild Boars in Corsica: Evaluating the Importance of Wild/Domestic Interactions and the Efficacy of Management Measures.

Front. Vet. Sci. 5:1

doi: 10.3389/fvets.2018.00001

\section{Aujeszky's Disease and Hepatitis E Viruses Transmission between Domestic Pigs and Wild Boars in Corsica: Evaluating the Importance of Wild/Domestic Interactions and the Efficacy of Management Measures}

\author{
François Charrier ${ }^{1,2 t}$, Sophie Rossi ${ }^{3 \dagger}$, Ferran Jori ${ }^{4,5}$, Oscar Maestrini', Céline Richomme ${ }^{6}$, \\ François Casabianca ${ }^{1}$, Christian Ducrot ${ }^{7}$, Johan Jouve ${ }^{8}$, Nicole Pavio $^{9}$ and \\ Marie-Frédérique Le Potier ${ }^{10 *}$

\begin{abstract}
Laboratoire de Recherche sur le Développement de l'élevage (LRDE), INRA, Corte, France, ${ }^{2}$ Laboratoire Interdisciplinaire, Sciences, Innovations, Sociétés, INRA, Marne-la-Vallée, France, ${ }^{3}$ Unité sanitaire de la Faune, Office National de la Chasse et de la Faune Sauvage, Gap, France, ${ }^{4}$ CIRAD, UMR ASTRE (Animal, Santé, Territoires, Risque et Environnement), Montpellier, France, ${ }^{5}$ ASTRE, University of Montpellier, CIRAD, INRA, Montpellier, France, ${ }^{6}$ Laboratoire de la rage et de la faune sauvage, ANSES, Nancy, France, ' UR346 EpiA, Centre de recherche Auvergne Rhône Alpes, INRA, Saint Genes-Champanelle, Virology, Animal Health Laboratory, ANSES-INRA-ENVA, Maisons-Alfort, France, ${ }^{10}$ Unité Virologie Immunologie Porcines, Laboratoire de Ploufragran/Plouzané, ANSES, Ploufragan, France
\end{abstract} \\ France, ${ }^{8}$ UMR Lieux, Identités, Espaces et Activités (LISA), CNRS-Université Pascal Paoli, Corte, France, ${ }^{9}$ UMR 1161
}

Wildlife species as reservoirs of infectious pathogens represent a serious constraint in the implementation of disease management strategies. In the Mediterranean island of Corsica, the dynamics of hepatitis E virus (HEV) and Aujeszky's disease virus (ADV) are suspected to be influenced by interactions between wild and domestic pigs. To improve our understanding of these influences, we first compared the seroprevalences of both viruses in domestic pig populations from different locations with contrasted levels of wild-domestic interactions, ADV vaccination, biosafety, and farm husbandry. Second, we performed an analysis at a more restricted geographical scale, to assess the matching of ADV or HEV prevalence between sympatric wild boar and outdoor pig farms most exposed to interactions with wildlife. Logistic models were adjusted to the observed data. A high seroprevalence of HEV (>80\%) and ADV (40\%) in pigs, with no significant difference according to the region, confirms that both pathogens are enzootic in Corsica. Vaccination against ADV had a strong protective effect, even when performed voluntarily by farmers. Farm biosafety had an additional effect on pigs' exposure, suggesting that contact between wild boars and pigs were involved in disease transmission. A strong correlation in HEV seroprevalence was observed between pigs and wild boars that were in close contact, and significantly lower seroprevalence was observed in pigs when they had little contact with wild boars due to spatial segregation. These results suggest a regular HEV circulation between sympatric wild boar and domestic pigs. The high HEV 
seroprevalence observed in domestic pigs (>80\%) suggests a spillover of the virus from domestic to wild populations through environmental contamination, but this hypothesis has to be confirmed. Conversely, even though avoiding sows' release on pasture during estrus showed some protecting effect in the free ranging pig farms regarding ADV, ADV seroprevalence was not dependent on the swine populations (wild or domestic) or on the wild-domestic spatial overlap, suggesting two quasi-separate enzootic cycles. This information will prove useful for designing more efficient disease management strategies in Corsica and similar contexts.

Keywords: Sus scrofa, wild boar, interface, virus transmission, Aujeszky's disease, hepatitis E, Corsica

\section{INTRODUCTION-CONTEXT: TWO POPULATIONS, TWO PATHOGENS, AND MULTIPLE STORIES}

Interactions between wild and domestic animals can play a role in the maintenance of pathogens and thereby compromise the efficiency of disease control strategies (1-3). Contacts may rely on direct (e.g., mating or fighting) and/or indirect transmission routes (e.g., sharing the same contaminated habitat) and can be influenced by human activities such as farming or hunting $(4,5)$. In extensive outdoor farming areas, wild/domestic interactions can be facilitated by some farming practices that expose domestic animals to contacts with wildlife (6). Similarly, hunting practices can influence the spatial distribution of game populations and their interactions with domestic animals. Wild and domestic swine are particularly at risk of inter-population transmission because they belong to the same species and share the same community of potential pathogens $(4,5,7)$. In this context, certain farming practices (use of shared pasture areas, reduced surveillance of the herd, etc.) can facilitate interactions and therefore, have a strong influence on the transmission and circulation of pathogens. On the other hand, biosecurity measures can prevent transmission from wild boars to domestic pigs in high-risk areas (8). The reproductive management of domestic sows during the estrus period can influence the occurrence of sexual interactions between wild boars and domestic females or fights between wild and domestic boars $(6,9)$. The risk of transmitting pathogens is considered the highest in areas with traditional extensive farming and can determine the dynamics of emerging or reemerging pig diseases (10).

In Corsica, a French Mediterranean island, traditional extensive outdoor pig farming systems remain common. Based on the use of local resources (pastures, chestnut, and oak forests), these systems produce high-quality processed meat for the local and national market. However, this kind of farming facilitates contacts with an important wild boar population, sharing pathogens such as the Aujeszky's disease virus (ADV) (11-14), hepatitis E virus (HEV) (15-18), or bovine tuberculosis (19). In addition, serious threats such as African swine fever, which is endemic in the neighboring island of Sardinia (20), increase the need to understand and manage wild-domestic pig interactions $(17,21)$.

The objective of this study is to explore the influence of different farming practices (biosafety, use of natural pastures/forests, ADV vaccination, and reproductive management) and individual factors (phenotype, age, sex, etc.) on the prevalence of two pathogens (ADV and HEV) known to circulate within and between domestic and wild pig populations in Corsica. These pathogens have different transmission routes, being able to infect new susceptible hosts through direct (requiring physical contact) or indirect (not requiring close proximity) interactions. $\mathrm{ADV}$, which remains enzootic among domestic pigs and wild boars on the island (22), can be transmitted by close contact including mating (23-25). In this case, the absence of reproductive management of sows can play a role on its transmission between wild and domestic populations. Conversely, HEV is a pathogen widely spread either by direct contact or through a contaminated environment, which is known to be common in free ranging populations of domestic pigs, wild boars and cross bred animals in Corsica and many other European countries $(16,17)$. We assumed that the dynamics of both pathogens can be influenced by different degrees of interaction at the wild/domestic interface and domestic pig management practices implemented by farmers.

To test these hypotheses, we implemented a two-step approach to investigate different risk factors. Initially, the seroprevalence of ADV and HEV was analyzed in the domestic pig population in a sample of farms across Corsica, to study the effect of the farm biosafety level, vaccination against ADV and the distribution of these two pathogens among different pig production systems and microregions in Corsica. Subsequently, we focused on traditional pig farms exposed to wild boar populations, located within one particular microregion from north-central Corsica (the BoziuVerde microregion), to better determine the effect of the spatial interface between the two swine populations (through the shared use of natural pastures and forests) and the protective effect of excluding sows in estrus from natural pastures.

\section{MATERIAL AND METHOD: COLLECTING DATA ON SEROPREVALENCE AND FARMING SYSTEMS IN A DOUBLE SCALED APPROACH}

To cover the potential diversity of extensive farming practices existing in Corsica, our study design incorporated an initial large scale, across-island approach to capture this diversity, and then focused on one specific microregion to assess the interaction 
between domestic pigs and wild boars (see Study Design: A TwoStep Study on Wild Boar/Domestic Pig Interactions in Corsica). We thus combined different sampling procedures (see Serological Data) to build three datasets for statistical modeling (see Dataset Construction and Data Analysis).

\section{Study Design: A Two-Step Study on Wild Boar/Domestic Pig Interactions in Corsica Domestic and Wild Swine Populations}

Corsica is a French Mediterranean island characterized by a sparse human population (32 inhabitants $/ \mathrm{km}^{2}$ ) and an economy principally based on tourism. Pig production is based on extensive outdoor systems, partly relying on pasture resources (acorns and chestnuts), using local and common breeds (Nustrale pigs, Large White, or Duroc), and generating products for several types of markets ("Protected Designation of Origin" products with high added value and short supply chains with direct sales). Pig farmers are thus breeders, but also processors and retailers of their own production as described in several other localities in the Mediterranean area (26). Pigs are slaughtered between November and March after the autumnal finishing period. However, although traditional farming systems are prevalent in Corsica, farming practices may differ greatly across the 300 registered farms, especially regarding epidemiological interactions with wild boars $(21,27)$.

On this mountainous island, extensively covered by grazing lands with typical Mediterranean vegetation (scrub, bushes, small trees, oak trees, etc.), the wild boar density is estimated to be very high, with around 30,000 wild boars being hunted every year (28). Because the wild and domestic populations share the same resources on the same areas, and sometimes at the same moment, this situation is of key interest to study infectious interactions between domestic and wild pigs.

\section{Two-Step Study: Large-scale Approach and Microregional Focus}

Both virus dynamics may rely on farming practices, such as biosecurity measures (e.g., fences), vaccination against ADV, and characteristics of the production system: age of slaughtering/hunting (farmers choose the age according to the quality of production output, hunters usually shoot older wild boars, etc.), mating management or spaying females (i.e., farmers may avoid encounters between the sow in estrus and male wild boars either by organizing sow mating before releasing them on pastures or by spaying them). These key factors were included in our datasets to be analyzed (see below). To capture the role of farming practices on pathogen dynamics, we combined two different approaches.

Step 1: Study Based on Sampling in Slaughterhouses (Dataset 1) The purpose of this part of the study was to determine the seroprevalence of both pathogens and their geographical distribution and to characterize the potential existing risk factors due to farming practices. To do so, we sampled domestic pigs opportunistically at slaughterhouses to obtain a spatially diversified picture of disease exposure from different areas of Corsica. This sample which was purposive and mainly driven by pragmatic opportunities included 213 pigs originating from 32 farms from several pig production areas across Corsica (Figures 1A,B): investigators collected blood samples during the slaughtering procedure and interviewed farmers when they came to slaughterhouses to bring their pigs or pick up the carcasses. Ten visits to the abattoirs were carried out during the main slaughtering period (December 2014-January 2015) to gage the overall status of each pathogen (HEV and ADV) and to identify the farming practices that play a role in pathogen dynamics.

\section{Step 2: Study Based on a Focus on a Particular Microregion} (Datasets 2 and 3)

The purpose was to produce knowledge on pathogen seroprevalence and distribution in domestic pig and wild boar population, targeting traditional outdoor pig farms, supposed to be at risk, from the Boziu-Verde microregion (cf., Figures 2A,B). Six farms were particularly selected for their irregular participation in vaccination campaigns (none of them participated to Aujeszky disease management plan implemented in 2011). Only one farm implemented techniques aiming at reducing risk of contact with wild boars (by female castration and reproduction management), and three of them were known to implement "informal" farming practices (i.e., unofficial farmers and on-farm slaughtering). By focusing on these farms, we hypothesized that the common extensive farming practices (i.e., the regular use of natural pastures) maximized the risk of pathogen transmission between both wild and domestic swine populations. We thus collected data on ADV and HEV seroprevalences and farming practices in pig farms, as well as ADV and HEV seroprevalence in wild boar populations (blood samples collected during hunting sessions, from August to January).

\section{Serological Data \\ Sample Collection}

To study the seroprevalence of these two diseases in the wild and domestic populations, serum samples were collected from wild boars and domestic pigs. For wild boars, blood samples were collected by hunters by means of cardiac puncture on recently shot animals. Blood samples from domestic pigs were collected by veterinarians at the slaughterhouse or by technicians in the herd by blotting filter paper with a drop of blood from the tail of sows.

Blood samples and dried filter papers were sent within 1 day to the INRA research facility in Corte to be centrifuged or dried, respectively. All sera were stored at $-20^{\circ} \mathrm{C}$, and dried filter papers were kept at $4^{\circ} \mathrm{C}$ until analysis.

\section{Serological Methods}

For ADV, all sera and filter papers were tested using an ELISA for the specific detection of antibodies to the ADV $g B$ protein (IdVet-ID Screen ${ }^{\circledR}$ Aujeszky gB competition), according to the manufacturer's instructions. Because pigs could have been vaccinated with a gE-deleted vaccine, the sera collected from the slaughterhouse were further tested with an ELISA gE (Idexx $\mathrm{PRV} / \mathrm{ADgI}$ ) when they tested $\mathrm{gB}$ positive in a vaccinated herd. These two commercial kits have been approved by the ANSESPloufragan OIE reference laboratory because they can detect, 

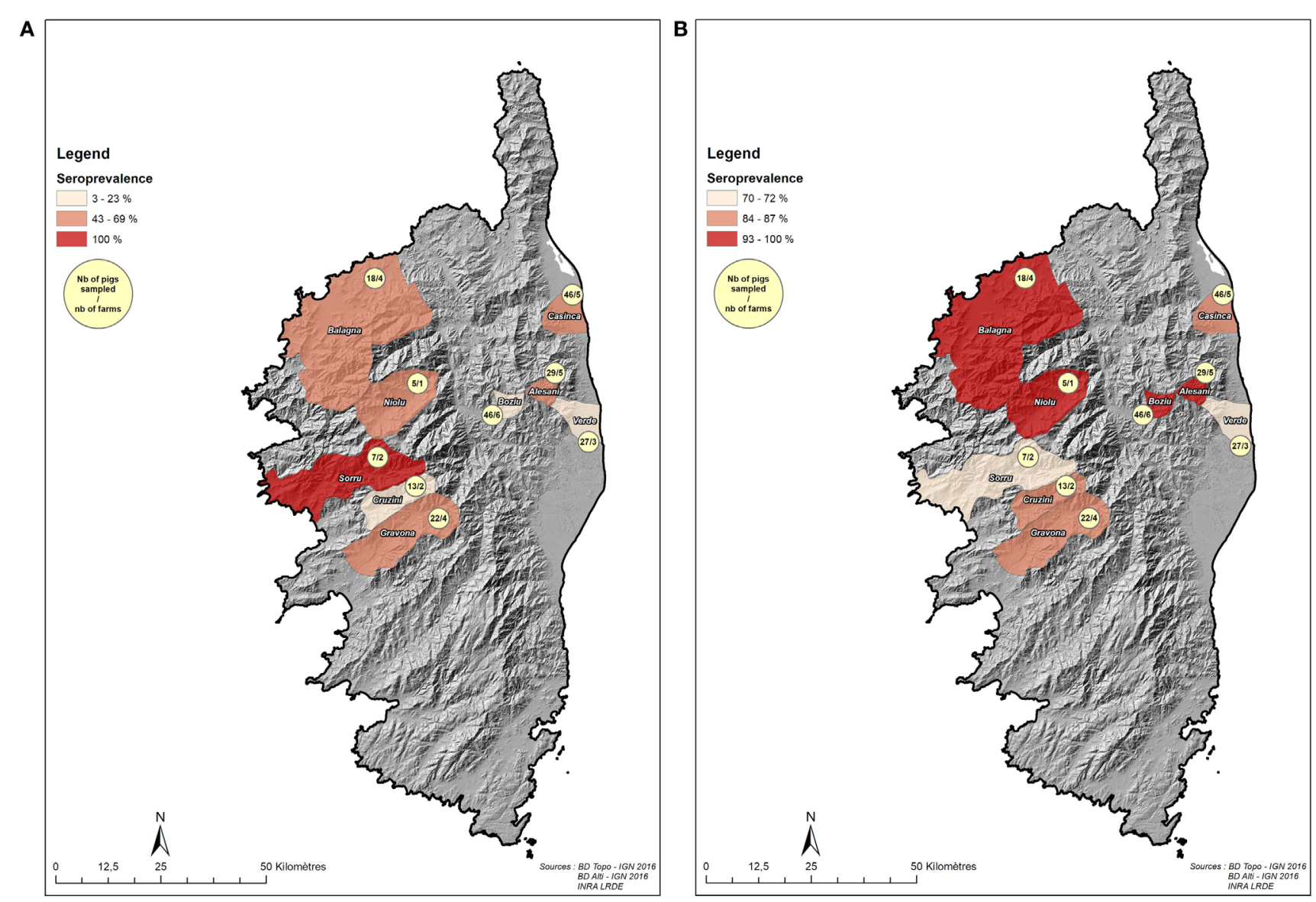

FIGURE 1 | Localization of sampled pigs sampled at the slaughterhouse (dataset 1). (A) Number of sampled pigs (slaughterhouse, dataset 1) at the scale of the nine samples microregions and Aujeszky's disease virus seroprevalence. (B) Number of sampled pigs (slaughterhouse, dataset 1) at the scale of the nine samples microregions and hepatitis E virus seroprevalence.
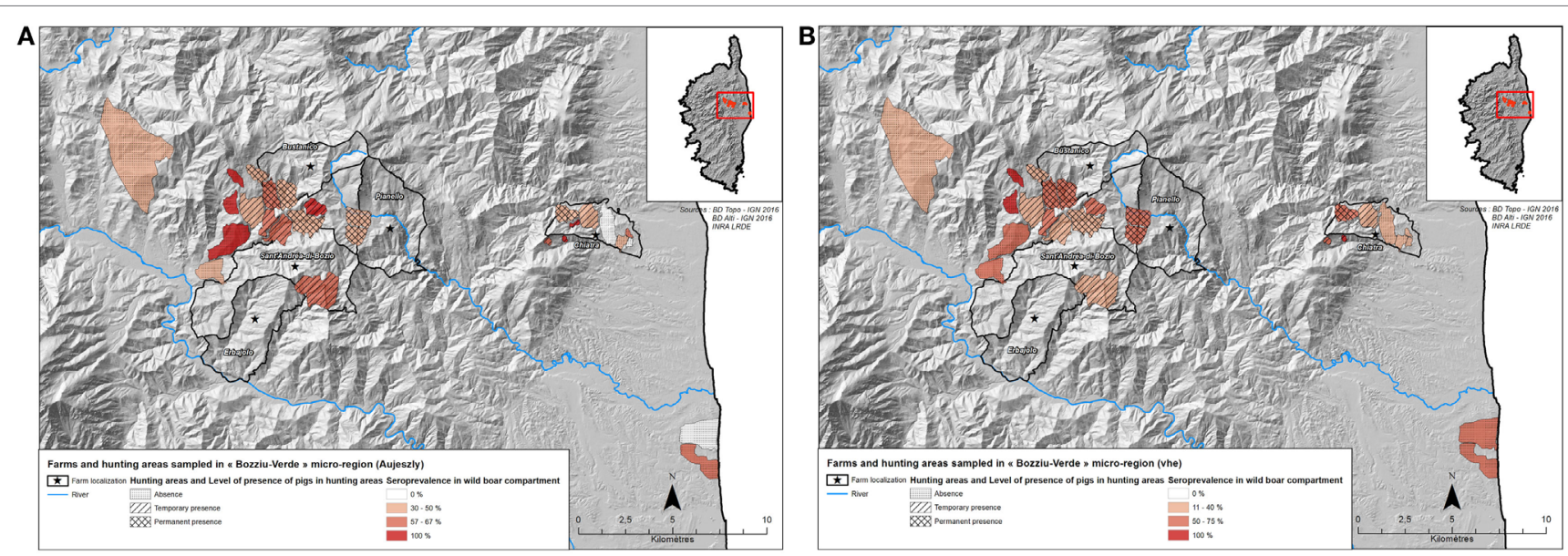

FIGURE 2 | Localization of sampled pigs and wild boars in the "Boziu-Verde" microregion (datasets 2 and 3). (A) Localization of domestic pigs sample and hunting areas with Aujeszky's disease virus seroprevalence. (B) Localization of domestic pigs sample and hunting areas with hepatitis E virus seroprevalence. 
respectively, the ADV-1 international serum standard at the dilutions of 1:2 for ELISA gB or 1:8 for ELISA gE.

The detection of anti-HEV antibodies in wild boars and domestic pigs was performed using the HEV ELISA 4.0v kit (MP Diagnostics, Illkirch, France) according to the manufacturer's instructions, except the serum quantity used, $10 \mu \mathrm{L}$ instead of $20 \mu \mathrm{L}$. For detection on filter paper, elution was performed in washing buffer. This sandwich ELISA allows the detection of all antibody classes (IgG, IgM, and IgA) and uses a recombinant antigen that is present in all HEV strains. Samples were positive when the optical density at $450 \mathrm{~nm}$ wavelength obtained for the sample was higher than the threshold defined as the mean for negative controls +0.3 for serum and +0.4 for filter paper.

\section{Dataset Construction and Data Analysis Datasets}

Three datasets were considered for the statistical analyses:

(1) Dataset 1: A total of 213 domestic pigs from 10 different microregions and 32 farms were sampled in slaughterhouses to assess the distribution of $\mathrm{HEV}$ and $\mathrm{ADV}$ in different parts of Corsica. Pig sera from vaccinated farms were tested for the presence of antibodies to $\mathrm{gB}$ and $\mathrm{gE}$ using the two ELISA tests to differentiate between vaccinated $(\mathrm{gB}+/$ $\mathrm{gE}-)$ and infected (gB+/gE+) animals. Pigs with two consecutive positive results were considered as exposed to ADV (i.e., seropositive), and those testing negative for $\mathrm{gB}$ or positive for $\mathrm{gB}$ but negative for $\mathrm{gE}$ were considered as noninfected (i.e., seronegative). In farms that did not vaccinate their pigs, only gB ELISAs were performed and all pigs with gB-positive results were considered as naturally infected with ADV (i.e., seropositive).

(2) Dataset 2: 80 domestic pigs were sampled on 6 traditional farms located in the Boziu-Verde microregion; these farms were not participating in the official vaccination plan and free ranging pigs shared natural pastures/forests with wild boars. For this sample, only gB ELISA was performed since no vaccination could interfere with surveillance.

(3) Dataset 3: A total of 297 wild boars were randomly sampled at seven different locations within the Boziu-Verde microregion during five hunting seasons, from 2009 to 2016. 198 sampled wild boars came from the four areas adjacent to farms sampled in dataset 2, and the 99 others came from the three areas that had no or limited contact with pigs (Figures 2A,B). Out of these 297 wild boars, 115 were young (i.e., less than 12 months old). For this sample, only gB ELISA was performed because wild boars are not vaccinated. This dataset is thus composed of 297 wild boars, randomly sampled in the Boziu-Verde area.

\section{Dependent and Independent Variables Individuals}

For both pigs and wild boars, serological data were categorized as positive and negative results (some rare doubtful results were removed) depending on the detection of ADV and HEV antibodies (dependent variables). The age of domestic pigs was determined by ear tags, whereas the age (young or adult) of wild boars was determined by tooth eruption patterns (29) and body size. Sex and the presence or absence of hybrid phenotype were also recorded. In boars, the presence of colors other than black or dark brown in the coat and the shape and length of the ears were considered as indicators of hybridization with domestic pigs (30). The "hybrid" category thus extended beyond just F1 generation.

\section{Farms}

For each pig farm, data were collected on its localization (see Figure 1), the level of biosafety of the pig farming area (three levels: free ranging, fenced pastures, and closed piggery), the vaccination treatment (three levels: no vaccination, unofficial vaccination, and official vaccination plan), spaying of females (two levels: yes and no), the reproductive management of female during estrus (two levels: yes and no). Among the six traditional farms sampled in dataset 2, we also recorded the use of natural pastures/forests (two levels: seasonal and permanent) and the type of animal [two levels: reproductive animals (breeder pigs) and pigs intended for meat production (fattening pigs)].

\section{Hunting Areas}

Hunting areas were classified according to the frequency of domestic pig presence during the year. Three types of hunting areas were distinguished according to hunters' observations: absence of pigs (no pigs at any time of the year); permanent presence (pigs are spotted on the area all year round); intermittent presence (pigs are spotted only during a specific period, autumn, and when they feed on chestnuts and acorns). Thus, each sampled wild boar was associated with a hunting area (28 areas), which was associated with a variable (3 levels) taking into account the proximity of domestic pigs.

\section{Statistical Model}

Individual serological results were encoded as 0 (seronegative) or one (seropositive). We used general linear model with logit link to test the risk factors of seropositivity for swine regarding both $\mathrm{ADV}$ and HEV. We also tested general mixed models, accounting for the random effects of farm (for pigs) and hunting sector (for wild boars) (data not shown). Since this approach did not provide any improvement in model fit, we finally selected the simplest general linear model approach.

Model selection was based on the Akaike information criterion corrected for over-dispersion and small sample size (QAICc). We performed a preliminary correlation analysis of explicative factors that revealed an important correlation between sow castration and the management sows during estrus in the first data set, so that we finally only tested the female castration treatment as a risk factor in the first step analysis. Starting from a "complete" model including all the potential explanatory variables for the different datasets (detailed in Table 1), we explored simpler models (using the dredge function of the $\mathrm{R}$ package MuMin). Considering the QAICc of all the potential sub-models, we used a model-averaging procedure to account for uncertainty in the model selection, because our data corresponded to a small sample size exposed 
TABLE 1 | Description of the models and variables tested for each dataset.

\begin{tabular}{|c|c|c|c|c|}
\hline Disease & Dataset & Number of animals & Complete model equation & \\
\hline \multirow[t]{3}{*}{$\begin{array}{l}\text { Aujeszky's disease virus } \\
\text { (ADV) }\end{array}$} & 1 & 151 pigs large scale & $\begin{array}{l}\text { Age + castration + microregion + seroHEV + sex + farm } \\
\text { type + vaccination }\end{array}$ & \\
\hline & 2 & 75 free ranging pigs (Boziu-Verde) & $\begin{array}{l}\text { Age + crossbred + pasture use + owner + sow } \\
\text { release + seroHEV + sex + repro status + zone }\end{array}$ & \\
\hline & 3 & 274 wild boar (Boziu-Verde) & Age + year + hybrid + seroHEV + sex + zone & \\
\hline \multirow[t]{3}{*}{ Hepatitis E virus (HEV) } & 1 & 151 pigs large scale & Age + castration + microregion + seroADV + sex + farm type & \\
\hline & 2 & 75 free ranging pigs (Boziu-Verde) & $\begin{array}{l}\text { Age + crossbred + pasture use + owner + sow } \\
\text { release + seroADV + sex + repro status + zone }\end{array}$ & \\
\hline & 3 & 274 wild boar (Boziu-Verde) & Age + year + hybrid + seroADV + sex + zone & \\
\hline \multicolumn{5}{|c|}{ (b) Explicative variables description } \\
\hline Subspecies & Individual/pop & Variable & Classes & Datasets \\
\hline Pig or wild boar & Individual & Age & Young/adult & $1-3$ \\
\hline Pig or wild boar & Individual & Sex & Male/female & $1-3$ \\
\hline Pig or wild boar & Individual & Hybrid status & Yes/no & 2 and 3 \\
\hline Pig & Individual & Reproductive status & Reproducer/fattening & 2 \\
\hline Pig/wild boar & Individual & Serological status for HEV or ADV & $0 / 1$ & $1-3$ \\
\hline Pig & Farm & Farm type & Closed/fenced pasture/traditional free ranging & 1 \\
\hline Pig & Farm & Vaccination & Official plan/self vaccination/no vaccination & 1 \\
\hline Pig & Farm & $\begin{array}{l}\text { Castration or sows in heat } \\
\text { management }\end{array}$ & $0 / 1$ & 1 and 2 \\
\hline Pig & Farm & Pasture use & Seasonal/all year round & 2 \\
\hline Pig & Farm & Microregion & Boziu, Casinca, Alesani, Gravonna, Plaine Orientale, Cruzzini & 1 \\
\hline Pig & Farm & Owner & 6 owners anonymized & 2 \\
\hline Pig or wild boar & $\begin{array}{l}\text { Farm of hunting } \\
\text { area }\end{array}$ & Area & 6 areas for wild boars and 4 areas for pigs & 2 and 3 \\
\hline
\end{tabular}

to uncontrolled sampling processes (at the slaughterhouse or of voluntary farms). That means that we could not necessarily retain a "single best model" but rather, a set of potentially "best models" for which the increase in QAICc (delta-QAICc) was less than 2 (31). We finally calculated variable coefficients [i.e., odd ratios and $95 \%$ confidence intervals (CIs)] over this set of "best models" according to the process described by Burnham and Anderson (31) (and using the AICmodavg R package). These analyses were performed using R software (32), and the MuMin (33), and AICmodavg packages (34).

\section{RESULTS}

\section{ADV and HEV Seroprevalence and Risk Factors in the Corsican Domestic Pig Population (Dataset 1)}

A total of 213 domestic pigs were sampled at the slaughterhouse, but the analyses were performed on the 151 individuals for which there were no missing data for any of explanatory variables or serological assays. Average seroprevalence in this dataset was $41.7 \%$ (95\% CI [33.8\%; 49.6\%]) for ADV and $85.4 \%(95 \%$ CI [79.8\%; 91.0\%]) for HEV. These values were higher in free ranging and fenced pasture farms than in closed farms [average prevalence was $58.4 \%$ (95\% CI [48.8\%; 68.0\%]) and 93.0\% (95\% CI $[88.1 \% ; 97.9 \%])$ in free ranging farms regarding $\mathrm{ADV}$ and $\mathrm{HEV}$, respectively].

\section{Major Risk Factors Associated with ADV Seropositivity in Pigs}

We retained three potential best models according to their QAICc values (delta-QAICc < 2) (QAICc are detailed in the additional materials), but the significant average effects only concerned the vaccination treatment, sow castration and farm biosafety (full model-averaged coefficients detailed in Table 2a). The vaccination treatment was negatively correlated to ADV prevalence: a lower seroprevalence was observed in farms that implemented a self-vaccination process $\left(\mathrm{OR}_{\mathrm{no}}\right.$ vaccination/self-vaccination $=3.88,95 \%$ CI $[1.30 ; 11.57])$, but this protective effect was much higher in farms that had implemented the official vaccination plan $\left(\mathrm{OR}_{\text {self-vaccination/official }}=3.39,95 \% \mathrm{CI}[1.07 ; 10.75]\right)$. We also observed a protective effect of sow castration $\left(\mathrm{OR}_{\text {no castration/castration }}=4.24,95 \% \mathrm{CI}\right.$ $[1.31 ; 13.71])$. Traditional free ranging farms exhibited a higher seroprevalence compared with the closed ones $\left(\mathrm{OR}_{\text {free ranging/close }}=6.14\right.$, 95\% CI [1.11;34.12]); the absence of ADV seropositive individual in fenced pasture farms in our sample could not allow the comparison of that particular category to other biosafety levels. All other effects were not significant and were finally not retained (Table 2a).

\section{Major Risk Factors Associated with HEV Seropositivity in Pigs}

We retained four potential best models according to their QAICc values (delta-QAICc < 2) (additional materials), but the significant average effects only concerned the farm biosafety (full model-averaged coefficients detailed in Table 2b). Traditional 
TABLE 2 | Parameters estimates among the set of best models (model averaging) for dataset 1 (pigs sampled at the slaughterhouse at a large scale).

\begin{tabular}{|c|c|c|c|c|c|}
\hline & Estimate & SE & Adjusted SE & z-Value & $\operatorname{Pr}(>|z|)$ \\
\hline \multicolumn{6}{|l|}{ (a) Regarding Aujeszky's disease virus } \\
\hline Vacc (no vs voluntary) & 1.35680 & 0.55691 & 0.56158 & 2.416 & $0.0157^{\star}$ \\
\hline Vacc (official vs voluntary) & -1.22555 & 0.58898 & 0.59395 & 2.063 & $0.0391^{\star}$ \\
\hline Type (free ranging vs closed) & 1.81566 & 0.87457 & 0.88168 & 2.059 & $0.0395^{\star}$ \\
\hline Sows' castration (yes) & -1.44539 & 0.59826 & 0.60331 & 2.396 & $0.0166^{\star}$ \\
\hline Type (open air vs closed) & -17.02230 & $1,279.67939$ & $1,290.48297$ & 0.013 & 0.9895 \\
\hline Age (young vs adult) & -0.15475 & 0.48168 & 0.48439 & 0.319 & 0.7494 \\
\hline Sex (male vs female) & -0.05546 & 0.23302 & 0.23456 & 0.236 & 0.8131 \\
\hline \multicolumn{6}{|l|}{ (b) Regarding hepatitis E virus } \\
\hline Type (fenced pasture and free ranging vs closed) & 2.30771 & 0.68869 & 0.69288 & 3.331 & 0.000867 \\
\hline Sows' castration (yes) & 0.04097 & 0.23187 & 0.23342 & 0.175 & 0.860689 \\
\hline Age (young) & -0.36303 & 0.67060 & 0.67264 & 0.540 & 0.589398 \\
\hline Sex (male) & -0.06955 & 0.26421 & 0.26562 & 0.262 & 0.793440 \\
\hline
\end{tabular}

*Significant p-value.

Significant parameters for each data set are indicated in bold.

TABLE 3 | Parameters estimates among the set of best models (model averaging) for dataset 2 (free ranging pigs from Boziu Verde).

\begin{tabular}{|c|c|c|c|c|c|}
\hline & Estimate & SE & Adjusted SE & z-Value & $\operatorname{Pr}(>|z|)$ \\
\hline \multicolumn{6}{|l|}{ (a) Regarding Aujeszky's disease virus } \\
\hline Sows mating management (yes) & -4.2114 & 1.1991 & 1.2180 & 3.458 & $0.000545^{\star}$ \\
\hline Reproductive status (yes) & 3.3042 & 1.2305 & 1.2473 & 2.649 & $0.008071^{*}$ \\
\hline Sex (male) & 1.8744 & 1.2264 & 1.2380 & 1.514 & 0.129999 \\
\hline Sero hepatitis E virus (HEV) (positive) & 1.3607 & 1.4478 & 1.4569 & 0.934 & 0.350327 \\
\hline Zone 2 (vs Zone 1) & -0.0454 & 0.6389 & 0.6505 & 0.070 & 0.944364 \\
\hline Zone 3 (vs Zone 1) & 5.9474 & $1,071.7341$ & $1,091.4423$ & 0.005 & 0.995652 \\
\hline Zone 4 (vs Zone 1) & 0.2780 & 0.9535 & 0.9631 & 0.289 & 0.772872 \\
\hline Pasture use (seasonal vs permanent) & 0.3833 & 1.0516 & 1.0627 & 0.361 & 0.718347 \\
\hline \multicolumn{6}{|l|}{ (b) Regarding HEV } \\
\hline Age (young vs adult) & -2.2175 & 0.7844 & 0.7956 & 2.787 & $0.00532^{\star}$ \\
\hline Pasture use (seasonal vs permanent) & -2.0819 & 0.9163 & 0.9314 & 2.235 & $0.02541^{\star}$ \\
\hline Sows management (yes) & 0.1078 & 0.3747 & 0.3784 & 0.285 & 0.77582 \\
\hline Sex (male vs female) & -0.3589 & 0.6538 & 0.6579 & 0.546 & 0.58538 \\
\hline Reproductive status (yes) & -1.5416 & 1.0227 & 1.0317 & 1.494 & 0.13511 \\
\hline
\end{tabular}

*Significant p-value.

Significant parameters for each data set are indicated in bold.

free ranging farms and fenced pasture farms both exhibited a much higher seropositivity compared with closed farms, we finally merged both categories fenced pasture and free ranging categories since these two categories exhibited the same risk level $\left(\mathrm{OR}_{\text {free ranging or open air } / \text { losed }}=10.05,95 \% \mathrm{CI}[2.61 ; 38.76]\right)$. Other effects were not significant and were finally not retained (Table $2 b$ ).

\section{Seroprevalence and Risk Factors in Domestic Pigs from Six Traditional}

\section{Farms in Boziu-Verde (Dataset 2)}

The analyses were performed on 75 pigs with no missing data for any of the explanatory variables and serological results. Average seroprevalence in this dataset was 48.0\% (95\% CI [36.7\%; 59.3\%]) for $\mathrm{ADV}$ and $30.7 \%$ (95\% CI [20.3\%; 41.1\%]) for HEV.

\section{Risk Factors Associated with ADV Seropositivity}

We retained six potential best models according to their QAICc values (delta-QAICc < 2) (additional materials), but significant average effects only concerned pig reproductive status and management of sows in estrus (full model-averaged coefficients detailed in Table 3a). Reproductive pigs were more at risk than others $\left(\mathrm{OR}_{\text {breeder/fattening }}=27.23,95 \% \mathrm{CI}[2.44 ; 303.68]\right)$ and the management of sows on estrus had a protective effect $\left(\mathrm{OR}_{\text {no management } / \text { mating management }}=67.45,95 \% \mathrm{CI}[6.43 ; 707.43]\right)$. Other effects were not significant and were finally not retained (Table $3 a$ ).

\section{Risk Factors Associated with HEV Seropositivity}

We retained four potential best models according to their QAICc values (delta-QAICc < 2) (additional materials), but significant average effects only concerned pigs' age and the intensity of natural pasture/forests use (full model-averaged coefficients detailed in Table $3 \mathrm{~b})$. Adult pigs were more at risk than young ones $\left(\mathrm{OR}_{\mathrm{adult} /}\right.$ young $=9.18,95 \%$ CI $[1.97 ; 42.73]$ ), and farms permanently using natural pastures/forests showed a higher risk than farms only using them in autumn $\left(\mathrm{OR}_{\text {permanent/autumn }}=8.02,95 \% \mathrm{CI}[1.33 ; 48.32]\right)$. Other effects were not significant and were finally not retained (Table 3b).

\section{Seroprevalence and Risk Factors of ADV and HEV in Wild Boar from Boziu-Verde (Dataset 3)}

Out of 297 wild boars sampled, 274 analysis could be performed (23 samples could not be analyzed because of sample quality 
defaults). Average seroprevalence in this dataset was of $45.1 \%$ (95\% CI [39.8\%; 50.4\%]) for $\mathrm{ADV}$ and $38.7 \%$ (95\% CI [33.2\%; $44.2 \%])$ for HEV.

\section{Risk Factors Associated with ADV Seropositivity}

We considered three potential best models according to their QAICc values (delta-QAICc < 2) (additional materials), but the significant average effects only concerned wild boar's age and wild boar seropositivity for HEV (full model-averaged coefficients detailed in Table 4a). Adult wild boars had a higher risk than young ones $\left(\mathrm{OR}_{\text {adult/young }}=3.80,95 \% \mathrm{CI}[2.14 ; 6.77]\right)$ and $\mathrm{HEV}$ seropositive animals were more at risk than seronegative ones $\left(\mathrm{OR}_{\mathrm{HEV}+/ \mathrm{HEV}-}=2.06,95 \% \mathrm{CI}[1.51 ; 3.52]\right)$. Other effects were not significant and were finally not retained (Table 4a).

\section{Risk Factors Associated with HEV Seropositivity}

We considered 11 potential best models according to their QAICc values (delta-QAICc < 2) (additional materials), but the significant average effects only concerned the intensity of pig presence on natural pastures/forests, the year 2014, and wild boar seropositivity regarding ADV (full model-averaged coefficients detailed in Table $4 \mathrm{~b}$ ). The hunting areas with permanent pig presence showed the highest seroprevalence $\left(\mathrm{OR}_{\text {permanent/other }}=3.63,95 \%\right.$ CI $[1.12 ; 11.71])$, while the seasonal use of pasture did not show higher seroprevalence than areas with no pig presence $(p=0.53)$. As previously observed, $\mathrm{HEV}$ and ADV serological status were correlated $\left(\mathrm{OR}_{\text {aujeszky+/aujeszky- }}=2.36,95 \% \mathrm{CI}[1.37 ; 4.08]\right)$. Year 2014 appeared at risk compared with other years. However, this result relied on a very low sample on that year and might thus correspond to a particular family/spatial cluster rather than a real year effect $\left(\mathrm{OR}_{2014 / \text { other }}=9.07,95 \%\right.$ CI $\left.[1.92 ; 42.87]\right)$. Other effects were not significant and were finally not retained (Table $4 \mathrm{~b}$ ).

\section{DISCUSSION}

We explored seroprevalence regarding two infectious pathogens corresponding to different transmission patterns (ADV with direct transmission; HEV with direct and indirect transmission routes) at the interface of wild and domestic swine in Corsica. During the first step, we observed pigs' seroprevalences at a large scale. Regarding both diseases, the high seroprevalence observed in all pig age classes and the absence of differences in seroprevalence among the different microregions confirmed the enzootic situation in Corsican pigs. Regarding ADV, our results confirmed the protective effect of vaccination. The official vaccination plan proposed by the French animal health authorities ${ }^{1}$ (35) between 2011 and 2013 is highly effective in comparison with farms that do no vaccinate their pigs and also compared with the partial protective effect of vaccination performed outside the official vaccination plan. Regarding both diseases, we observed a higher risk in free ranging pig farms (and open air fenced farms for HEV) than in intensive indoor ones, suggesting that the wild boar/pig interface and/or extensive farming practices in the contact with the natural environment might play a role in the exposure to both diseases.

Concerning free ranging pig farms, we confirmed the protective effect of limiting the release of sows during estrus on pastures for ADV seroprevalence (i.e., by mating sows before transferring them to natural pastures/forests), suggesting a risk linked to contacts with wild boars and highlighting the value of mating management limiting ADV transmission on free ranging farms. We also observed a higher ADV seroprevalence in breeder pigs than fattening ones, which may reflect the higher risk of breeders and their longer life compared with fattening pigs. These results are consistent with the expected sexual transmission pattern associated with ADV and the polygynous reproductive pattern observed in swine. The level of seroprevalence was similar in wild boars and pigs (i.e., 40-45\%) and matched with previous studies performed in Corsica confirming the fact that ADV has been circulating for a long time in both wild and domestic

${ }^{1}$ Fédération Régionale des Groupements de Défense Sanitaire de Corse (FRGDSB20), 2014. Plan Expérimental de lutte contre la maladie d'AujeszkyBilan après trois années de mise en œuvre. Technical report presented in Ajaccio, on the 19th of September 2014. This report presents the technical results of the Aujeszky disease management strategy implemented by Health Authorities in Corsica from 2011 to 2014.

TABLE 4 | Parameters estimates among the set of best models (model averaging) for dataset 3 (hunted wild boar from Boziu Verde).

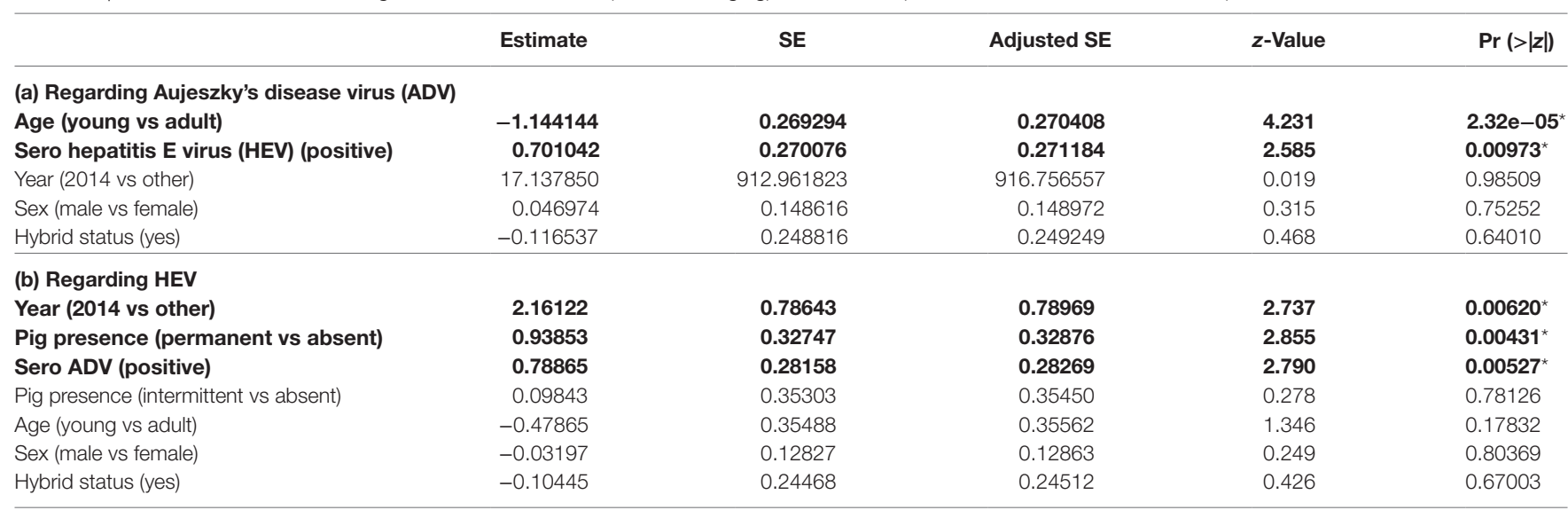

*Significant $p$-value.

Significant parameters for each data set are indicated in bold. 
populations $(11,12)$. This is one of the highest seroprevalence rates observed in wild boars in France (12) although wild boars are not as intensively managed in Corsica as in Central-Southern Spain $(36,37)$. We did not observe any additional risk in areas where free ranging pigs shared natural pastures/forest with wild boar, suggesting that the sylvatic and domestic epidemiological cycles are mostly independent even though the two populations are sympatric and sexual transmission is known to occur. In other European countries being in a situation of strict segregation, such as in Germany and continental Northern Italy, a complete asynchrony has been observed and different virus strains have been identified in the wild and domestic swine populations $(38,39)$. In our study, unmanaged domestic sows had a higher risk of becoming infected than other individuals, suggesting that sylvatic and domestic cycles are partly connected and that managing female in estrus limits the risk of ADV spill over. In addition, even if recent studies describe endemic patterns of ADV in wild boar populations, through female social behavior favoring intraspecific contacts $(40,41)$, further studies aiming at genotyping circulating virus strains, describing the space use and the genetic flow between domestic and wild populations are needed to better characterize these connections.

Regarding HEV, the study suggests a twofold lower exposure in wild boars $(<40 \%)$ compared with domestic pig populations $(>85 \%)$. The higher seroprevalence observed in domestic pigs suggests the spillover of HEV from pigs to wild boar rather than the contrary. However, since only wild boar populations from the Boziu-Verde were sampled in our study, we recommend a larger wild boar surveillance design, extended to other microregions combined with virus investigation and typing, to confirm this hypothesis. In free ranging farms (dataset 2), apparent seroprevalence (30\%) was lower than expected when considering data set 1 (>90\%); such a gap might correspond to a lower sensitivity of the serological ELISA test when using filter papers (used for dataset 1) instead of sera (used for dataset 2). The effect of domestic pig presence in hunting areas on wild boar seroprevalence suggests that inter-transmission does occur at the wild/domestic interface, possibly through environmental contamination and common attractors (e.g., contaminated water or food sources), as suggested by previous studies $(16,17)$. Nevertheless, the precise environmental risk factors (such as the role of water sources) for HEV transmission are still unclear and should be explored further in the future (42). Recent studies have suggested that hybrid wild boar populations might be more susceptible to certain infectious diseases than pure specimens $(43,44)$, and this association was also observed in Corsica when the prevalence of HEV was compared in populations of pure and hybrids wild boars (17). This potential role of hybrids was not confirmed by our analysis: once the use of natural habitats was taken into account, the hybrid status of wild boars was no longer significant, and we did not observe an additional risk in the domestic crossbred animals sampled in farms. These results suggest a confounding effect between animal population sympatry and the occurrence of hybrid individuals (these two factors being highly correlated) rather than a potential role of hybrids in HEV transmission between both populations. However, our data were based on phenotypical classification of hybrids which might not be precise enough to discern accurately between hybrid and pure individuals. Further studies using appropriate genetic methods to determine hybridization $(45,46)$ are needed to assess the hypothetical link between hybridization and disease susceptibility in Corsica.

Our results suggest that ADV and HEV infections can occur simultaneously in domestic pigs and wild boars. To the best of our knowledge, this potential co-infection has never been investigated in domestic or wild pigs. Recent studies have shown that a co-infection between HEV and other immunosuppressive porcine viruses such as PRSS can influence HEV infection dynamics concerning times of excretion or maintenance of the virus in the liver $(47,48)$. Since ADV can also affect the liver, a co-infection with both viruses could potentially increase liver damage, but further studies are needed to explore the pathogenic effects of coinfection with both viruses. Since no synergic mechanisms have been described between these two swine pathogens to date, we rather hypothesize a possible effect of local aggregations factors (e.g., family groups, water, or food sources) that might facilitate the transmission of both contagious diseases in wild boar [such as described by Acevedo et al. (36) and Vicente et al. (49) in other Mediterranean areas].

It is important to mention that, as our results are only exploratory since they are based on small samples and exposed to biases, they should be taken with caution; it is obvious that other nonconsidered factors unrelated to the wild/domestic interface might influence wild boar and domestic pig exposure to diseases. The effect of the year 2014, while seroprevalence in wild boar was stable all over the other years for both diseases, could be due to such uncontrolled factors or a sampling bias (50).

Finally, if the exploratory character of our study shows interesting results, it is essential to formulate research perspectives to confirm and improve our findings. We focused on one microregion only (Boziu-Verde), as a first step to test our hypothesis, and a comparative approach with other microregions, with different characteristics (microregions without pig farming activities, for example, or with a different distribution of technically advanced farms, or with less numerous wild board presence, etc.), is strongly needed. Another perspective is to combine this type of study with molecular approaches to identify pathogen strains in wild boar and pig populations. In the case of HEV, several recent studies have shown that several strains are shared between pigs, wild boars, pork products, and humans $(16,51)$. Such approaches can be relevant to address the question of environmental contamination (52). Concerning ADV, a major issue is the technical difficulty to collect samples containing the virus, as Aujeszky's disease symptoms are difficult to notice in free ranging farming systems.

\section{CONCLUSION}

To the best of our knowledge, this study represents the very first attempt to assess the use of disease seroprevalence values as indicators of the importance of wild boar/domestic pig interactions and the potential efficacy of disease management strategies for preventing disease maintenance and spread in an extensive pig farming environment such as the one occurring in Corsica. It provides evidence of the strong protective effect of $\mathrm{ADV}$ vaccination, 
which should encourage farmers to commit to future vaccination programs. Moreover, we provide evidence of the benefits of reproductive management of sows (i.e., spaying or mating before release them into natural habitats). In the future, the cost-effectiveness of such measures on farm productivity (e.g., average litter size or pig growth rate) needs to be quantified. Our study highlighted a limited protective effect of pig farm biosecurity measures toward both diseases, suggesting that the wild/domestic interactions are possibly not the only one and nor the most important factor explaining disease dynamics in Corsican pigs. Our study provides evidence of the connection between wild and domestic disease cycles on traditional free ranging farms and the usefulness of promoting seasonal partial segregation of the swine populations. However, awareness needs to be raised among farmers and hunters on the likely presence of other unknown/uncontrolled factors unrelated to the wild/domestic pig interface. Therefore, further analysis and confirmation of these identified trends is recommended to explore the potential impact of other factors affecting the transmission of those pathogens and to better understand their dynamics and the impact of management measures.

\section{ETHICS STATEMENT}

The study was exempt of authorization because the serological analysis were carried out on blood samples collected either on live pigs by veterinarian technicians at the farm level or at the slaughterhouse as part of a surveillance scheme, or on shot wild boars by hunters.

\section{REFERENCES}

1. Haydon DT, Cleaveland S, Taylor LH, Laurenson MK. Identifying reservoirs of infection: a conceptual and practical challenge. Emerg Infect Dis (2002) 8(12):1468-73. doi:10.3201/eid0812.010317

2. Rhyan JC, Nol P, Quance C, Gertonson A, Belfrage J, Harris L, et al. Transmission of brucellosis from elk to cattle and bison, Greater Yellowstone area, USA, 2002-2012. Emerg Infect Dis (2013) 19(12):1992-5. doi:10.3201/ eid1912.130167

3. Gortazar C, Diez-Delgado I, Barasona JA, Vicente J, De La Fuente J, Boadella M. The wild side of disease control at the wildlife-livestock-human interface: a review. Front Vet Sci (2014) 1:27. doi:10.3389/fvets.2014.00027

4. Jori F, Relun A, Trabucco B, Charrier F, Maestrini O, Chavernac D, et al. Questionnaire-based assessment of wild boar/domestic pig interactions and implications for disease risk management in Corsica. Front Vet Sci (2017) 4:198. doi:10.3389/fvets.2017.00198

5. Jori F, Payne A, Stahl A, Nava A, Rossi S. Wild and feral pigs: disease transmission at the interface between wild and domestic pig species in the old and the new world. In: Melletti M, Meijaard E, editors. Ecology, Evolution and Management of Wild Pigs and Peccaries (Chap. 35), Cambridge: Cambridge University Press (2017). p. 388-403. Implications for Conservation.

6. Wu N, Abril C, Thomann A, Grosclaude E, Doherr M, Boujon P, et al. Risk factors for contacts between wild boar and outdoor pigs in Switzerland and investigations on potential Brucella suis spill-over. BMC Vet Res (2012) 8:116. doi:10.1186/1746-6148-8-116

7. Hars J, Garin-Bastuji B, Richomme C, Payne A, Rossi S. De léradication à la réapparition des maladies infectieuses animales. Les dangers de la faune sauvage: contexte et outils de gestion. Épidémiol et Santé Anim (2013) 64:57-69.

8. Vicente-Rubiano M, Martinez-Lopez B, Sanchez-Vizcaino F, SanchezVizcaino JM. A new approach for rapidly assessing the risk of Aujeszky's disease reintroduction into a disease-free Spanish territory by analysing the movement of live pigs and potential contacts with wild boar. Transbound Emerg Dis (2012) 61:350-61. doi:10.1111/tbed.12041

\section{AUTHOR CONTRIBUTIONS}

The two first authors contributed equally: FCharrier and SR. Conceived and designed the seroprevalence studies: FCharrier, OM, and FCasabianca. Performed the studies: FCharrier, FJ, OM, and FCasabianca. Analyzed the data: FCharrier, SR, FJ, CR, and FCasabianca. Carried out the statistical analyses: SR. Contributed reagents/materials/analysis tools: FCharrier, OM, FCasabianca, NP, M-FL, and JJ. Wrote the paper: SR and FCharrier. Critically read the manuscript: FJ, CR, CD, NP, and M-FL. Read and approved the final manuscript: FCharrier, SR, FJ, OM, CR, FCasabianca, CD, NP, and M-FL.

\section{ACKNOWLEDGMENTS}

The authors thank Marie Pellerin and Aurélie Oger for technical assistance with HEV and Aujeszky's disease analysis. The authors also thank the farmers and hunters for their help in sampling operations and for their participation in interviews.

\section{FUNDING}

This work was partly funded by the INRA-GISA Metaprogramme (Integrated Management of Animal Health, PaCMan) and by the European Union Seventh Framework Programme under grant agreement no. 311931 (ASFORCE).

9. Wyckoff C, Henke SE, Campbell T, Hewitt DG, VerCauteren KC. Feral swine contact with domestic swine: a serologic survey and assessment of potential for disease transmission. J Wildl Dis (2009) 45:422-9. doi:10.7589/ 0090-3558-45.2.422

10. Mur L, Sánchez-Vizcaíno JM, Fernández-Carrión E, Jurado C, Rolesu S, Feliziani F, et al. Understanding African swine fever infection dynamics in Sardinia using a spatially explicit transmission model in domestic pig farms. Transbound Emerg Dis (2017):1-12. doi:10.1111/tbed.12636

11. Casabianca F, Picard P, Sapin JM, Gautier JF, Vallée M. Contribution à l'épidémiologie des maladies virales en élevage porcin extensif. Application à la lutte contre la maladie d’Aujeszky en Région Corse. Journ Rech Porc France (1989) 21:153-60.

12. Rossi S, Hars J, Garin-Bastuji B, Le Potier M-F, Boireau P, Aubry P, et al. Résultats de l'enquête nationale sérologique menée chez le sanglier sauvage (2000-2004). Bulletin épidémiologique Afssa/DGAL (2008) 29:5-7.

13. Agence Française de Sécurité Sanitaire des Aliments. Avis de l'Agence française de sécurité sanitaire des aliments sur un projet d'arrêté fixant les mesures techniques et administratives relatives à la mise en oeuvre d'une prophylaxie médicale, de la maladie d'Aujeszky chez les espèces domestiques réceptives dans les départements de Haute-Corse et de Corse du Sud. Paris: Afssa/DGAL (2009). 14 p.

14. Ruiz-Fons F, Vidal D, Höfle U, Vicente J, Gortázar C. Aujeszky's disease virus infection patterns in European wild boar. Vet Microbiol (2007) 120:241-50. doi:10.1016/j.vetmic.2006.11.003

15. Meng XJ, Lindsay DS, Sriranganathan N. Wild boars as sources for infectious diseases in livestock and humans. Philos Trans R Soc Lond B Biol Sci (2009) 364(1530):2697-707. doi:10.1098/rstb.2009.0086

16. Pavio N, Laval M, Maestrini O, Casabianca F, Charrier F, Jori F. Possible foodborne transmission of hepatitis $\mathrm{E}$ virus from domestic pigs and wild boars from Corsica. Emerg Infect Dis (2016) 22(12):2197-9. doi:10.3201/ eid2212.160612

17. Jori F, Laval M, Maestrini O, Casabianca F, Charrier F, Pavio N. Assessment of domestic pigs, wild boars and feral hybrid pigs as reservoirs of hepatitis E virus in Corsica, France. Viruses (2016) 8(8):236. doi:10.3390/v8080236 
18. Ruiz-Fons F. A review of the current status of relevant zoonotic pathogens in wild swine (Sus scrofa) populations: changes modulating the risk of transmission to humans. Transbound Emerg Dis (2017) 64:68-88. doi:10.1111/ tbed.12369

19. Richomme C, Boschiroli ML, Hars J, Casabianca F, Ducrot C. Bovine tuberculosis in livestock and wild boar on the Mediterranean island, Corsica. J Wildl Dis (2010) 46(2):627-31. doi:10.7589/0090-3558-46.2.627

20. Mur L, Atzeni M, Martínez-López B, Feliziani F, Rolesu S, Sanchez-Vizcaino JM. Thirty-five-year presence of African swine fever in Sardinia: history, evolution and risk factors for disease maintenance. Transbound Emerg Dis (2016) 63:e165-e177. doi:10.1111/tbed.12264

21. Relun A, Charrier F, Trabucco B, Maestrini O, Molia S, Chavernac D, et al. Multivariate analysis of traditional pig management practices and their potential impact on the spread of infectious diseases in Corsica. Prev Vet Med (2015) 121(3-4):246-56. doi:10.1016/j.prevetmed.2015.07.004

22. Albina E, Mesplede A, Chenut G, Le Potier MF, Bourbao G, Legal S, et al. A serological survey on classical swine fever (CSF), Aujeszky's disease (AD) and porcine reproductive and respiratory syndrome (PRRS) virus infections in French wild boars from 1991 to 1998. Vet Microbiol (2000) 77:43-57. doi:10.1016/S0378-1135(00)00255-8

23. Pejsak ZK, Truszczynski MJ. Aujeszky’s disease (pseudorabies). In: Straw BE, Zimmerman JJ, D’Allaire S, Taylor DJ, editors. Diseases of Swine. Ames, USA: Blackwell Publishing (2006). p. 419-33.

24. Pol F, Le Potier MF. Herpèsvirose chez Le porc: La maladie d'Aujeszky. Bulletin de l'Académie Vétérinaire de France (2011) 164(4):323-6. doi:10.4267/ 2042/48103

25. Verin R, Varuzza P, Mazzei M, Poli A. Serologic, molecular, and pathologic survey of pseudorabies virus infection in hunted wild boars (Sus scrofa) in Italy. J Wildl Dis (2014) 50(3):559-65. doi:10.7589/2013-01-004

26. Casabianca F, Matassino D. Local resources and typical animal products. In: Rubino R, Sepe L, Dimitriadou A, Gibon A, editors. Livestock Farming Systems: Product Quality Based on Local Resources Leading to Improved Sustainability. (Vol. 118), Benevento: EAAP Publication (2006). p. 9-26.

27. Trabucco B, Charrier F, Jori F, Maestrini O, Cornelis D, Etter E, et al. Stakeholder's practices and representations of contact between domestic and wild pigs: a new approach for disease risk assessment? Acta Agric Slov Suppl (2013) 4:119-22.

28. ONCFS. Tableaux de Chasse Ongulés Sauvagess. Supplément Faune Sauvage. (2012). 8 p. Available from: http://www.oncfs.gouv.fr/IMG/file/mammiferes/ ongules/tableau/FS296_tableaux_chasse_ongules.pdf

29. De Buruaga M, Lucio AJ, Purroy FJ. Reconocimiento de Sexo y Edad en Especies Cinegeticas. Vitoria, Spain: Diputacion Foral de Alava (1991). 127 p.

30. Mayer J, Brisbin I. Distinguishing feral hogs from introduced wild boar and their hybrids: a review of past and present efforts. Texas Natural Widllife. San Angelo, TX: Agrilife Research and Extension Center, Texas A\&M University (1997).

31. Burnham KP, Anderson DR. Model Selection and Multimodel Inference A Practical Information-Theoretic Approach. 2nd ed. New York, USA: Springer Verlag (2002).

32. R Core Team. R: A Language and Environment for Statistical Computing. Vienna: R Foundation for Statistical Computing (2017).

33. Bartoń K. MuMIn: Multi-Model Inference. (2017). Available from: https:// cran.r-project.org/web/packages/MuMIn/MuMIn.pdf

34. Mazerolle MJ, Mazerolle MMJ. Package AICcmodavg. (2017). Available from: http://camoruco.ing.uc.edu.ve/cran/web/packages/AICcmodavg/ AICcmodavg.pdf

35. FRGDS. Plan Expérimental de lutte contre la maladie d'Aujeszky - Bilan après trois années de mise en oeuvre. Technical report. Ajaccio (2014).

36. Acevedo P, Escudero MA, Muńoz R, Gortázar C. Factors affecting wild boar abundance across an environmental gradient in Spain. Acta Theriol (2006) 51(3):327-36. doi:10.1007/BF03192685

37. Boadella M, Gortázar C, Vicente J, Ruiz-Fons F. Wild boar: an increasing concern for Aujeszky's disease control in pigs? BMC Vet Res (2012) 8(1):7. doi:10.1186/1746-6148-8-7
38. Müller T, Hahn EC, Tottewitz F, Kramer M, Klupp BG, Mettenleiter TC, et al. Pseudorabies virus in wild swine: a global perspective. Arch Virol (2011) 156(10):1691-705. doi:10.1007/s00705-011-1080-2

39. Chiari M, Ferrari N, Bertoletti M, Avisani D, Cerioli M, Zanoni M, et al. Longterm surveillance of Aujeszky's disease in the alpine wild boar (Sus scrofa). Ecohealth (2015) 12:563-70. doi:10.1007/s10393-015-1064-x

40. González-Barrio D, Martín-Hernando MP, Ruiz-Fons F. Shedding patterns of endemic Eurasian wild boar (Sus scrofa) pathogens. Res Vet Sci (2015) 102:206-11. doi:10.1016/j.rvsc.2015.08.014

41. Touloudi A, Valiakos G, Athanasiou LV, Birtsas P, Giannakopoulos A, Papaspyropoulos K, et al. A serosurvey for selected pathogens in Greek European wild boar. Vet Rec Open (2015) 2:e000077. doi:10.1136/vetreco2014-000077

42. Kukielka E, Barasona JA, Cowie CE, Drewe JA, Gortazar C, Cotarelo I, et al. Spatial and temporal interactions between livestock and wildlife in South Central Spain assessed by camera traps. Prev Vet Med (2013) 112(3-4):213-21. doi:10.1016/j.prevetmed.2013.08.008

43. Wu J, Liu S, Zhou S, Wang Z, Li K, Zhang Y, et al. Porcine reproductive and respiratory syndrome in hybrid wild boars, China. Emerg Infect Dis (2011) 17:1071-3. doi:10.3201/eid/1706.101518

44. Goedbloed D, Van Hooft P, Walburga L, Megens H, van Wieren S, Ydenberg R, et al. Increased Mycoplasma hyopneumoniae disease prevalence in domestic hybrids among free-living wild boar. Ecohealth (2015) 12:571-9. doi:10.1007/ s10393-015-1062-z

45. Nikolov IS, Stoeckle BC, Markov G, Kuehn R. Substantial hybridisation between wild boars (Sus scrofa scrofa) and East Balkan pigs (Sus scrofa $f$. domestica) in natural environment as a result of semi-wild rearing in Bulgaria. Czech J Anim Sci (2017) 62(1):1-8. doi:10.17221/49/2015-CJAS

46. Šprem N, Salajpal K, Safner T, Đikić D, Jurić J, Curik I, et al. Genetic analysis of hybridization between domesticated endangered pig breeds and wild boar. Livest Sci (2014) 162:1-4. doi:10.1016/j.livsci.2013.12.010

47. Salines M, Barnaud E, Andraud M, Eono F, Renson P, Bourry O, et al. Hepatitis $\mathrm{E}$ virus chronic infection of swine co-infected with porcine reproductive and respiratory syndrome virus. Vet Res (2015) 46:55. doi:10.1186/ s13567-015-0207-y

48. Salines M, Andraud M, Rose N. From the epidemiology of hepatitis E virus (HEV) within the swine reservoir to public health risk mitigation strategies: a comprehensive review. Vet Res (2017) 48:31. doi:10.1186/s13567-017-0436-3

49. Vicente J, Barasona JA, Acevedo P, Ruiz-Fons JF, Boadella M, Diez-Delgado I, et al. Temporal trend of tuberculosis in wild ungulates from Mediterranean Spain. Transbound Emerg Dis (2013) 60(s1):92-103. doi:10.1111/tbed.12167

50. Nàhlik $A$, Cahill $S$, Cellina $S$, Gàl J, Jànoska $F$, Rosell $C$, et al. Wild boar management in Europe: knowledge and practice. In: Melletti M, Meijaard E, editors. Ecology, Conservation and Management of Wild Pigs and Peccaries. Cambridge: Cambridge University Press (2017). p. 339-53.

51. Mazzei M, Nardini R, Verin R, Forzan M, Poli A, Tolari F. Serologic and molecular survey for hepatitis E virus in wild boar (Sus scrofa) in Central Italy. New Microbes New Infect (2015) 7:41-7. doi:10.1016/j.nmni.2015.05.008

52. Barth S, Blome S, Cornelis D, Pietschmann J, Laval M, Maestrini O, et al Faecal Escherichia coli as biological indicator of contact between domestic pigs and wild boar (Sus scrofa) in Corsica. Transbound Emerg Dis (2018). doi:10.1111/tbed.12799

Conflict of Interest Statement: The authors declare that the research was conducted in the absence of any commercial or financial relationships that could be construed as a potential conflict of interest.

Copyright ( 2018 Charrier, Rossi, Jori, Maestrini, Richomme, Casabianca, Ducrot, Jouve, Pavio and Le Potier. This is an open-access article distributed under the terms of the Creative Commons Attribution License (CC BY). The use, distribution or reproduction in other forums is permitted, provided the original author(s) or licensor are credited and that the original publication in this journal is cited, in accordance with accepted academic practice. No use, distribution or reproduction is permitted which does not comply with these terms. 